\title{
Treatment of gestational diabetes diagnosed by the IADPSG criteria decreases excessive fetal growth
}

Kyoung-Hee Lee, MD¹, You-Jung Han, MD, PhD¹, Jin-Hoon Chung, MD, PhD ${ }^{1}$, Moon-Young Kim, MD, PhD', Hyun-Mee Ryu, MD, PhD², Jin-Ha Kim, MD³ , Dong-Wook Kwak, MD, PhD ${ }^{4}$, Sung-Hoon Kim, MD, PhD ${ }^{5}$, Seongwoo Yang, $\mathrm{MPH}^{6}$, Minhyoung Kim, MD, $\mathrm{PhD}^{7}$

\begin{abstract}
Department of Obstetrics and Gynecology, ${ }^{1} \mathrm{CHA}$ Gangnam Medical Center, CHA University, Seoul, ${ }^{2} \mathrm{CHA}$ Bundang Medical Center, $\mathrm{CHA}$ University, Seongnam, ${ }^{3}$ Samsung Medical Center, Seoul, ${ }^{4}$ Ajou University School of Medicine, Suwon, ${ }^{5}$ Department of Internal Medicine, Yonsei University Wonju College of Medicine, Wonju, ${ }^{6}$ Institute of Health and Environment, Seoul National University, Seoul, ${ }^{7}$ Department of Obstetrics and Gynecology,

MizMedi Hospital, Seoul, Korea
\end{abstract}

\section{Objective}

We evaluated the effect on treatment using the new International Association of Diabetes and Pregnancy Study Group (IADPSG) criteria for gestational diabetes mellitus (GDM) diagnosis.

\section{Methods}

Singleton pregnant women whose plasma glucose levels were $\geq 140 \mathrm{mg} / \mathrm{dL}$ on the $50 \mathrm{~g}$ glucose challenge test (GCT) underwent $75 \mathrm{~g}$ oral glucose tolerance for GDM diagnosis. During the first half of the study period, GDM was diagnosed using 2 abnormal values by Carpenter-Coustan (C-C) criteria. In the second half of the study period, 1 or more abnormal values by IADPSG criteria were used for GDM diagnosis. Pregnant women were classified into 5 groups: normal $50 \mathrm{~g} \mathrm{GCT}$, positive $50 \mathrm{~g} \mathrm{GCT}$ but non-GDM, GDM by IADPSG criteria and non-treated, GDM by IADPSG criteria and treated, GDM by C-C criteria and treated. The odds ratios (ORs) for large for gestational age (LGA) and macrosomia were analyzed.

\section{Results}

Of the 2,678 patients, the frequency of GDM diagnosed by C-C and IADPSG criteria was $2.6 \%$ and $7.5 \%$. ORs (95\% confidence intervals [Cls]) for LGA and macrosomia in the group with GDM by IADPSG criteria and non-treated were $2.81(95 \% \mathrm{Cl}, 1.47-5.38)$ and $2.84(95 \% \mathrm{Cl}, 1.08-7.47)$. The risk of LGA and macrosomia did not increase in the group with GDM by IADPSG criteria and treated.

\section{Conclusion}

The risk of LGA and macrosomia for mild GDM diagnosed solely by IADPSG criteria depends on whether they are treated or not. Treatment of GDM based on IADPSG criteria reduces the risk of excessive fetal growth.

Trial Registration

Clinical Research Information Service Identifier: КCT0000776

Keywords: Gestational diabetes; Criteria; Treatment

\section{Introduction}

In 1964, O'Sullivan and Mahan [1] proposed specific criteria for gestational diabetes mellitus (GDM), developed to anticipate type 2 diabetes in mothers after delivery. Based on their diagnostic criteria, there are different glucose cutoffs and strategies to diagnose GDM [2]. In order to reach a consensus in the diagnostic method for GDM and focus on pregnancy complications, the Hyperglycemia and Adverse
Received: 2019.03.04. Revised: 2019.05.23. Accepted: 2019.06.25. Corresponding author: Minhyoung Kim, MD, PhD Department of Obstetrics and Gynecology, MizMedi Hospital, 295 Gangseo-ro, Gangseo-gu, Seoul 07639, Korea E-mail: obdrmhk@naver.com https://orcid.org/0000-0002-5510-8049

Articles published in Obstet Gynecol Sci are open-access, distributed under the terms of the Creative Commons Attribution Non-Commercial License (http://creativecommons org/licenses/by-nc/3.0/) which permits unrestricted non-commercial use, distribution, and reproduction in any medium, provided the original work is properly cited.

Copyright $\odot 2020$ Korean Society of Obstetrics and Gynecology 


\title{
Obstetrics \& Gynecology Science
}

\author{
Vol. 63, No. 1, 2020
}

Pregnancy Outcome (HAPO) study was conducted [3]. In 2010, based on the HAPO study results, the International Association of Diabetes and Pregnancy Study Group (IADPSG) suggested a universal screening for GDM by 1-step $75 \mathrm{~g}$ oral glucose tolerance tests (OGTTs) with new cut-off values [4].

The new IADPSG recommendation diagnosed GDM with only 1 abnormality in the cut-off values. As a consequence, more women who had mild hyperglycemia were diagnosed with GDM. The World Health Organization and the American Diabetes Association have adopted this new recommendation $[5,6]$. However, because of the higher incidence of GDM (18\% in the U.S.) and little evidence of cost-effectiveness of the new criteria, the American College of Obstetrician and Gynecologists continues to endorse a 2-step approach and diagnostic test by $100 \mathrm{~g} \mathrm{OGTT} \mathrm{[7].}$

Since the new recommendation of the IADPSG, several studies reported that treatment based on the IADPSG criteria improved pregnancy outcomes. However, those studies were retrospective, and the comparison groups were women with normal glucose tolerance or GDM determined through different glucose cut-off values or diagnostic methods, such as $100 \mathrm{~g} \mathrm{OGTT} \mathrm{[8-10].} \mathrm{A} \mathrm{recent} \mathrm{study} \mathrm{reported} \mathrm{that} \mathrm{no} \mathrm{differ-}$ ences were noted between untreated and treated patients diagnosed by the IADPSG criteria [11]. Furthermore, evidence of improvements in perinatal outcomes of the treatment of milder GDM by the IADPSG criteria is still limited. We prospectively evaluated the perinatal outcomes in patients with GDM by the new strict cut-offs of the IADPSG, whether they were treated or not.

\section{Materials and methods}

From March 2013 through November 2017, we collected a prospective cohort composed of singleton pregnant women in a single institution. Women with multiple gestations, women who gave birth in another hospital, and women who underwent a diagnostic OGTT at other clinics were excluded.

Our institution diagnosed GDM through a 2-step method. All women were universally screened with a 1-hour, $50 \mathrm{~g}$ glucose challenge test (GCT) between 24 and 28 gestational weeks. Women with positive screening (glucose $\geq 140 \mathrm{mg} / \mathrm{dL}$ ) underwent a 2-hour $75 \mathrm{~g}$ OGTT for GDM diagnosis.

We divided the study period into 2 sub-periods and applied different diagnostic criteria for GDM. During the first 2 years
(March 2013 to December 2015), we diagnosed GDM based on 2 or more values exceeding the Carpenter-Coustan (CC) thresholds [12]. In the following 2 years (January 2016 to November 2017), we diagnosed GDM based on 1 or more values exceeding the new IADPSG thresholds [4]: fasting $\geq 92 \mathrm{mg} / \mathrm{dL}$, 1-hour $\geq 180 \mathrm{mg} / \mathrm{dL}$, and 2-hour $\geq 153 \mathrm{mg} / \mathrm{dL}$. Among the study subjects belonging to the first sub-period of the study, some women were classified as normal and not treated when the new IADPSG thresholds were applied. All women diagnosed with GDM during the 2 study periods received the same management, including diet, exercise, selfmonitoring of glucose levels 4 times daily, and, if necessary, insulin therapy.

The study population was categorized in 5 groups: group 1, negative result in $50 \mathrm{~g} \mathrm{GCT}$; group 2, positive result in $50 \mathrm{~g}$ GCT but normal in $75 \mathrm{~g}$ OGTT; group 3, GDM diagnosed by IADPSG criteria and non-treated; group 4, GDM diagnosed by IADPSG criteria and treated; group 5, GDM diagnosed by $\mathrm{C}-\mathrm{C}$ criteria and treated. The 5 groups did not overlap. Women in groups 3 and 4 had only 1 abnormal value by IADPSG criteria or 2 or more abnormal values belonging to the following levels: fasting glucose at 92-94 mg/dL, 1-hour glucose $\geq 180 \mathrm{mg} / \mathrm{dL}$, and 2-hour glucose at 153-154 mg/dL.

Data recorded from the pregnant women included age, parity, body mass index (BMI) pre-pregnancy, smoking and alcohol intake pre-pregnancy, family history of diabetes mellitus, and total gestational weight gain (GWG).

The perinatal outcomes included gestational weeks at delivery, birthweight of neonate, cesarean delivery, preterm delivery (<37 completed weeks), large for gestational age (LGA; $\geq 90$ th percentile), macrosomia $(\geq 4.0 \mathrm{~kg})$, small for gestational age (SGA; $<10$ th percentile), shoulder dystocia, birth tract laceration of third degree or more, Apgar score, admission to neonatal intensive care unit (NICU), neonatal intubation, and phototherapy for neonatal jaundice. Birth weight criteria used for defining LGA and SGA were based on Korean data [13].

The $\chi^{2}$ test and analysis of variance (ANOVA) were utilized for the comparison of variables. The Tukey test was used for post hoc testing of ANOVA. Multivariate logistic regression analysis was used to identify the odds ratios (ORs) of the different GDM groups for the risk of adverse outcomes while adjusting for potential confounders. The reference group was women with negative results in $50 \mathrm{~g} \mathrm{GCT}$. SAS version 9.4 (SAS Institute, Cary, NC, USA) was used for statistical analysis. 


\section{Obstetrics \& Gynecology Science}

Kyoung-Hee Lee, et al. Treatment of GDM by the IADPSG criteria

\section{Results}

A total of 2,678 pregnant women were included in this cohort. Of those, 1,979 (73.9\%) women had negative results in the $50 \mathrm{~g} \mathrm{GCT}$. Of the 699 women with positive results in the $50 \mathrm{~g} \mathrm{GCT}, 70$ (2.6\%) had 2 abnormal values by C-C criteria and received treatment (Fig. 1). During the first half of the study period, 52 women $(1.9 \%)$ who had 1 or more abnormal values by the IADPSG cut-off values, not C-C criteria, were diagnosed as non-GDM and did not receive treatment. During the second half of the study period, 79 women (3.0\%) were diagnosed solely by IADPSG criteria as GDM and received treatment. The frequency of GDM diagnosed by IADPSG criteria in our study population was $7.5 \%$.

The maternal age was significantly younger in the negative $50 \mathrm{~g} \mathrm{GCT}$ group (Table 1). The BMI was significantly higher in groups with GDM by either IADPSG or C-C criteria. The GWG of women diagnosed with GDM by IADPSG or C-C criteria and treated was significantly lower than that of nonGDM women. Maternal characteristics were not different between treated and not-treated women diagnosed with GDM by IADPSG criteria.

Each blood glucose value in the $75 \mathrm{~g}$ OGTT of women diagnosed with GDM by C-C criteria (fasting glucose $95.0 \pm 12.2 \mathrm{mg} / \mathrm{dL}$, 1-hour glucose $194.8 \pm 24.2 \mathrm{mg} / \mathrm{dL}$, 2-hour glucose $170.1 \pm 25.6 \mathrm{mg} / \mathrm{dL}$ ) was significantly higher

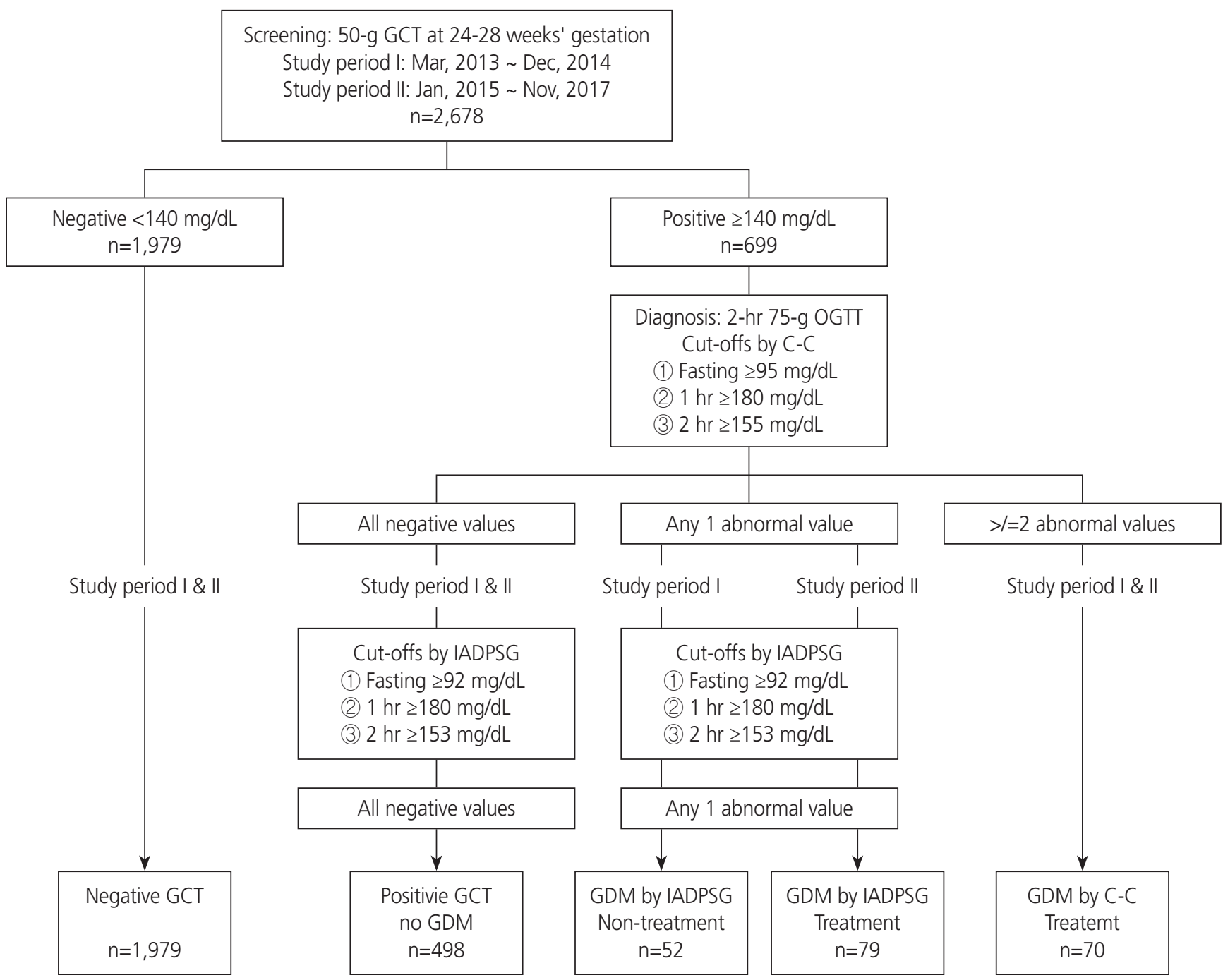

Fig. 1. Enrollment of study population. GCT, glucose challenge test; C-C, Carpenter-Coustan; IADPSG, International Association of Diabetes and Pregnancy Study Group; GDM, gestational diabetes mellitus. 


\title{
Obstetrics \& Gynecology Science
}

\author{
Vol. 63, No. 1, 2020
}

than that of women diagnosed with GDM by IADPSG criteria and treated (fasting glucose $87.1 \pm 7.1 \mathrm{mg} / \mathrm{dL}$, 1-hour glucose $166.3 \pm 22.4 \mathrm{mg} / \mathrm{dL}$, 2-hour glucose $148.2 \pm 19.4 \mathrm{mg} / \mathrm{dL}$ ) $(P<0.001)$. No difference was noted between each blood glucose level in the $75 \mathrm{~g}$ OGTT between treated and not-treated women diagnosed with GDM by IADPSG criteria.

Table 2 shows the perinatal outcomes of the study population. The mean birthweight of neonates was highest in women diagnosed with GDM by IADPSG criteria and not treated, and this was significantly different from neonatal birthweight of the negative $50 \mathrm{~g} \mathrm{GCT}$ group. The rate of LGA was also highest in women diagnosed with GDM by IADPSG criteria and not treated. The rate of macrosomia was highest in women diagnosed with GDM by C-C criteria and treated, followed by that of women diagnosed with GDM by IADPSG criteria and not treated. The rate of cesarean section was also highest in women diagnosed with GDM by C-C criteria and treated. The rates of SGA and other perinatal outcomes were not different among the 5 groups.

In order to evaluate whether the treatment of GDM diagnosed by IADPSG criteria independently affects perinatal outcomes, we performed multivariate logistic regression analysis after adjusting for age, parity, and BMI pre-pregnancy (Table 3). The risk of macrosomia was increased in women diagnosed with GDM by C-C criteria and treated (OR, 2.61; 95\% confidence interval, 1.11-6.14). Women diagnosed with GDM by IADPSG criteria and non-treated showed significantly higher ORs of LGA, macrosomia, and preterm delivery. However, the women diagnosed with GDM by IADPSG criteria and treated did not increase the risk of LGA, macrosomia, and preterm delivery but they had an increased risk of a low Apgar score at 5 minutes and neonatal intubation.

\section{Discussion}

This study evaluated the perinatal complications in GDM by the new strict cut-offs of diagnostic criteria, whether they were treated or not. Here, the treatment of women with GDM diagnosed by IADPSG criteria showed similar pregnancy outcomes compared with women with normal pregnancies. In contrast, the non-treatment of GDM diagnosed by IADPSG criteria independently increased the risk of LGA, macrosomia, and preterm birth. GDM diagnosed by C-C criteria, i.e., higher glucose values in OGTT, also showed an increased risk of macrosomia, although it was treated.

Prior to the HAPO study, there had been reports of treatment of mild GDM reducing pregnancy complications, such as fetal overgrowth and cesarean section $[14,15]$. Those studies applied 2-step approaches and used different OGTTs for the diagnosis of GDM. Crowther et al. diagnosed mild GDM by a fasting glucose $<140 \mathrm{mg} / \mathrm{dL}$ and 2-hour glucose after a 75 g loading, 140-198 mg/dL [14]. Another study defined mild GDM by a fasting glucose level $<95 \mathrm{mg} / \mathrm{dL}$ and 2 or more abnormal values in a 3-hour $100 \mathrm{~g}$ OGTT: 1-hour, $180 \mathrm{mg} / \mathrm{dL}$; 2-hour, $155 \mathrm{mg} / \mathrm{dL}$; and 3-hour, $140 \mathrm{mg} / \mathrm{dL}$ [15].

Table 1. Maternal characteristics of the study population

\begin{tabular}{|c|c|c|c|c|c|c|}
\hline Characteristics & $\begin{array}{c}\text { Negative } 50 \mathrm{~g} \\
\text { GCT } \\
(n=1,979)\end{array}$ & $\begin{array}{c}\text { Positive } 50 \mathrm{~g} \\
\text { GCT no-GDM } \\
\quad(n=498)\end{array}$ & $\begin{array}{l}\text { GDM by } \\
\text { IADPSG non- } \\
\text { treatment } \\
(n=52)\end{array}$ & $\begin{array}{c}\text { GDM by } \\
\text { IADPSG } \\
\text { treatment } \\
(n=79)\end{array}$ & $\begin{array}{c}\text { GDM by C-C } \\
\text { treatment } \\
(n=70)\end{array}$ & $P$-value \\
\hline Age (yr) & $33.1 \pm 3.7$ & $34.1 \pm 3.8^{\mathrm{a})}$ & $34.3 \pm 3.5$ & $34.6 \pm 3.9^{a}$ & $35.5 \pm 3.4^{\mathrm{a})}$ & $<0.001$ \\
\hline BMI pre-pregnancy $\left(\mathrm{kg} / \mathrm{m}^{2}\right)$ & $20.6 \pm 2.8$ & $20.7 \pm 2.8$ & $22.1 \pm 3.6^{a, b)}$ & $22.9 \pm 3.7^{a, b)}$ & $23.4 \pm 3.7^{a, b)}$ & $<0.001$ \\
\hline Multiparity & $770(38.9)$ & $215(43.2)$ & $30(57.6)$ & $37(46.8)$ & $37(52.8)$ & 0.004 \\
\hline Smoking at pre-pregnancy & $205(10.3)$ & $63(12.6)$ & $9(17.3)$ & $11(13.9)$ & $12(17.1)$ & 0.112 \\
\hline Alcohol at pre-pregnancy & $1,655(83.6)$ & $408(81.9)$ & $40(76.9)$ & $70(88.6)$ & $53(75.7)$ & 0.151 \\
\hline Family history of DM & $519(26.2)$ & $147(29.5)$ & $13(25.0)$ & $33(41.7)$ & $33(47.1)$ & $<0.001$ \\
\hline Total GWG (kg) & $13.5 \pm 4.4$ & $13.1 \pm 4.0$ & $12.4 \pm 4.6$ & $10.2 \pm 5.4^{\mathrm{a}, \mathrm{b})}$ & $10.2 \pm 5.7^{\mathrm{a}, \mathrm{b})}$ & $<0.001$ \\
\hline Insulin therapy & - & - & - & $6(7.9)$ & $23(32.8)$ & - \\
\hline
\end{tabular}

BMI, body mass index; C-C, Carpenter-Coustan; DM, diabetes mellitus; GCT, glucose challenge test; GDM, gestational diabetes mellitus; GWG, gestational weight gain; IADPSG, International Association of Diabetes and Pregnancy Study Group; OGTT, oral glucose tolerance test.

${ }^{\text {a) }} P<0.05$ compared with negative $50 \mathrm{~g} \mathrm{GCT;}{ }^{\text {b) }} P<0.05$ compared with positive $50 \mathrm{~g}$ GCT but no-GDM. 


\section{Obstetrics \& Gynecology Science}

Kyoung-Hee Lee, et al. Treatment of GDM by the IADPSG criteria

Those studies treated women who had lower glucose levels than the original cut-off values for GDM diagnosis [1]. The HAPO researchers focused on pregnancy complications and suggested lower diagnostic criteria because of increased pregnancy complications in proportion to the blood glucose levels of OGTT. In our study, each blood glucose level in a 2-hour $75 \mathrm{~g}$ OGTT of GDM diagnosed by IADPSG criteria was lower than that of GDM diagnosed by C-C criteria and, notably, the fasting glucose levels were below $90 \mathrm{mg} / \mathrm{dL}$. However, the risk of pregnancy complications including LGA, macrosomia, and preterm delivery was increased if the women were not treated. Our findings complement the HAPO results. A retrospective study also reported that an untreated group of women diagnosed with GDM by IADPSG criteria had a higher birthweight and LGA than a normal group [16]. In addition to the association between mild hyperglycemia and perinatal complications similar to the HAPO results, our data showed that the treatment of mild hyperglycemia reduced LGA and macrosomia.

Since the IADPSG proposal of new criteria for GDM diag-

Table 2. Pregnancy outcomes of 5 groups classified by the results of screening and diagnosis of gestational diabetes mellitus (GDM) by different criteria and treatment

\begin{tabular}{|c|c|c|c|c|c|c|}
\hline Characteristics & $\begin{array}{c}\text { Negative } 50 \mathrm{~g} \\
\text { GCT } \\
(n=1,979)\end{array}$ & $\begin{array}{l}\text { Positive } 50 \mathrm{~g} \\
\text { GCT no-GDM } \\
\quad(n=498)\end{array}$ & $\begin{array}{l}\text { GDM by } \\
\text { IADPSG non- } \\
\text { treatment } \\
(n=52)\end{array}$ & $\begin{array}{c}\text { GDM by } \\
\text { IADPSG } \\
\text { treatment } \\
(n=79)\end{array}$ & $\begin{array}{l}\text { GDM by C-C } \\
\text { treatment } \\
(n=70)\end{array}$ & $P$-value \\
\hline Delivery weeks & $38.9 \pm 1.4$ & $38.8 \pm 1.5$ & $38.8 \pm 2.2$ & $38.6 \pm 1.6$ & $38.6 \pm 1.1$ & 0.033 \\
\hline Neonatal birthweight (g) & $3,242 \pm 427$ & $3,257 \pm 436$ & $3,461 \pm 532^{a, b)}$ & $3,299 \pm 456$ & $3,331 \pm 461$ & 0.003 \\
\hline Male sex of neonate & $994(50.2)$ & $265(53.2)$ & $30(57.6)$ & $38(48.1)$ & $40(57.1)$ & 0.448 \\
\hline Cesarean delivery & $758(38.3)$ & $216(43.3)$ & $17(32.6)$ & $37(44.8)$ & $37(52.8)$ & 0.016 \\
\hline $\begin{array}{l}\text { Indication of cesarean } \\
\text { delivery }\end{array}$ & & & & & & 0.084 \\
\hline Repeat & $241(31.8)$ & $60(27.7)$ & $8(47.1)$ & $16(43.2)$ & $15(40.5)$ & \\
\hline FTP & $259(34.2)$ & $78(36.1)$ & $3(17.6)$ & $8(21.6)$ & $9(24.3)$ & \\
\hline NRFS & $58(7.6)$ & $11(5.1)$ & $3(17.6)$ & $2(5.4)$ & 0 & \\
\hline Maternal request & $54(7.1)$ & $22(10.2)$ & $1(5.9)$ & $6(1.6)$ & $5(13.6)$ & \\
\hline Malpresentation & $69(9.1)$ & $18(8.3)$ & $1(5.9)$ & $3(8.1)$ & $4(10.8)$ & \\
\hline Myomectomy & $44(2.2)$ & $18(8.3)$ & $1(5.9)$ & $2(5.4)$ & $1(2.7)$ & \\
\hline Others & $33(1.7)$ & $9(4.2)$ & 0 & 0 & $3(8.1)$ & \\
\hline LGA & $182(9.2)$ & $51(10.2)$ & $14(27.0)$ & $10(12.6)$ & $13(18.6)$ & $<0.001$ \\
\hline Macrosomia & $64(3.2)$ & $11(2.2)$ & $5(9.6)$ & $6(7.5)$ & $7(10.0)$ & 0.001 \\
\hline SGA & $209(10.5)$ & $56(11.2)$ & $1(1.9)$ & $5(6.3)$ & $5(7.1)$ & 0.279 \\
\hline Preterm delivery & $88(4.4)$ & $24(4.8)$ & $6(11.5)$ & $5(6.3)$ & $4(5.7)$ & 0.176 \\
\hline Shoulder dystocia & 0 & 0 & 0 & 0 & 0 & - \\
\hline Birth tract injury & $78(3.9)$ & $28(5.6)$ & $1(1.9)$ & $2(2.5)$ & $3(4.3)$ & 0.395 \\
\hline Apgar score $<7$ at $1 \mathrm{~min}$ & $52(2.6)$ & $17(3.4)$ & $2(3.8)$ & $4(5.0)$ & 0 & 0.329 \\
\hline Apgar score $<7$ at 5 min & $9(0.4)$ & $4(0.8)$ & 0 & $2(2.5)$ & 0 & 0.129 \\
\hline Admission to NICU & $226(11.4)$ & $60(12.0)$ & $5(9.6)$ & $15(18.9)$ & $4(5.7)$ & 0.139 \\
\hline Neonatal intubation & $87(4.4)$ & $27(5.4)$ & $3(5.7)$ & $8(10.1)$ & $3(4.2)$ & 0.185 \\
\hline Phototherapy & $545(27.5)$ & $139(27.9)$ & $16(30.7)$ & $26(32.9)$ & $25(35.7)$ & 0.491 \\
\hline
\end{tabular}

C-C, Carpenter-Coustan; FTP, failure to progress; GCT, glucose challenge test; IADPSG, International Association of Diabetes and Pregnancy Study Group; LGA, large for gestational age; NICU, neonatal intensive care unit; NRFS, nonreassuring fetal status; SGA, small for gestational age.

a) $P<0.05$ compared with negative $50 \mathrm{~g} \mathrm{GCT}$; ${ }^{\text {b) }} P<0.05$ compared with positive $50 \mathrm{~g} \mathrm{GCT}$ but no-GDM. 


\section{Obstetrics \& Gynecology Science}

Vol. 63, No. 1, 2020

Table 3. Multivariate logistic regression analysis for the association of gestational diabetes mellitus (GDM) treatment by different criteria and risk of pregnancy outcomes

\begin{tabular}{lccccc}
\hline Characteristics & $\begin{array}{c}\text { Negative } \mathbf{5 0 ~ g ~} \\
\text { GCT }\end{array}$ & $\begin{array}{c}\text { Positive } \mathbf{5 0 ~ g ~ G C T} \\
\text { no-GDM }\end{array}$ & $\begin{array}{c}\text { GDM by IADPSG } \\
\text { non-treatment }\end{array}$ & $\begin{array}{c}\text { GDM by IADPSG } \\
\text { treatment }\end{array}$ & $\begin{array}{c}\text { GDM by C-C } \\
\text { treatment }\end{array}$ \\
\hline Cesarean delivery & 1.0 (referent) & $1.16(0.95-1.43)$ & $0.67(0.37-1.22)$ & $1.08(0.68-1.73)$ & $1.26(0.76-2.08)$ \\
LGA & 1.0 (referent) & $1.09(0.78-1.52)$ & $2.81(1.47-5.38)$ & $1.01(0.50-2.05)$ & $1.54(0.80-2.96)$ \\
Macrosomia & 1.0 (referent) & $0.66(0.34-1.27)$ & $2.84(1.08-7.47)$ & $2.01(0.82-4.90)$ & $2.61(1.11-6.14)$ \\
SGA & 1.0 (referent) & $1.06(0.77-1.46)$ & $0.21(0.03-1.52)$ & $0.60(0.24-1.52)$ & $0.70(0.27-1.82)$ \\
Preterm delivery & 1.0 (referent) & $1.03(0.65-1.64)$ & $2.67(1.10-6.48)$ & $1.30(0.50-3.35)$ & $1.11(0.40-3.19)$ \\
Apgar score <7 at 1 min & 1.0 (referent) & $1.29(0.73-2.26)$ & - & $2.30(0.79-6.71)$ & - \\
Apgar score <7 at 5 min & 1.0 (referent) & $1.81(0.55-5.96)$ & $0.79(0.31-2.01)$ & $5.88(1.18-29.36)$ & - \\
Admission to NICU & 1.0 (referent) & $1.04(0.77-1.42)$ & $0.79(0.31-2.01)$ & $1.61(0.90-2.91)$ & $0.40(0.14-1.13)$ \\
Neonatal intubation & 1.0 (referent) & $1.22(0.78-1.91)$ & $1.33(0.40-4.37)$ & $2.23(1.03-4.87)$ & $0.86(0.26-2.83)$ \\
Phototherapy & 1.0 (referent) & $0.97(0.78-1.22)$ & $1.17(0.64-2.14)$ & $1.15(0.70-1.88)$ & $1.25(0.75-2.10)$ \\
\hline
\end{tabular}

Data are expressed as odds ratios (95\% confidence internal) using negative $50 \mathrm{~g} \mathrm{GCT}$ as reference and are adjusted for maternal age, parity, and body mass index before pregnancy.

C-C, Carpenter-Coustan; GCT, glucose challenge test; IADPSG, International Association of Diabetes and Pregnancy Study Group; LGA, large for gestational age; NICU, neonatal intensive care unit; SGA, small for gestational age.

nosis, several studies comparing the IADPSG criteria with older C-C or National Diabetes Data Group (NDDG) criteria have reported improved pregnancy outcomes with increased cost savings, while others did not. Duran et al. [17] assessed the cost-benefits between 1-step IADPSG and 2-step C-C methods. The 1-step IADPSG method resulted in a higher GDM diagnosis ( $35.5 \%$ vs. $19.6 \%$, respectively) but improved the pregnancy outcomes of gestational hypertension, preterm birth, cesarean section, and LGA. The estimated saved costs were $€ 14,358$ per 100 women. Another study in Asia compared the intervention outcomes between the IADPSG and NDDG criteria [18]. The intervention of GDM according to the IADPSG lowered pregnancy complications compared to NDDG. In contrast, a retrospective study in the U.S. reported that 1-step screening with the IADPSG criteria did not decrease the number of LGA or macrosomic neonates but increased the rate of primary cesarean delivery [19]. In their study, the prenatal BMI of that study population was $26.1 \mathrm{~kg} / \mathrm{m}^{2}$, higher than the BMI $\left(22.9 \mathrm{~kg} / \mathrm{m}^{2}\right)$ of our population. Obesity in pregnant women is also well-known risk factor for many pregnancy complications and it may lessen the effects of treatment of mild hyperglycemia. In our study, even after adjusting for maternal weight, the treatment of women with GDM diagnosed by IADPSG criteria decreased the risk of LGA and macrosomia, which are closely associated with hyperglycemia. The risks of neonatal intubation and an
Apgar score $<7$ at 5 minutes were also increased in women diagnosed with GDM by the IADPSG cut-off values and in the treatment group. Unlike fetal growth, these immediate neonatal outcomes might be more associated with other intrapartum or obstetric factors other than hyperglycemia. Another analysis concluded that the 1-step IADPSG proposal for GDM was beneficial only if pregnant women were counseled after child birth and received treatment to prevent long-term diabetes [20]. Although the IADPSG recommended integrating screening and diagnosis for GDM in 2011, there is still debate on treatment benefits and there is a lack of consensus on establishing a uniform method for diagnosing GDM.

The glucose values for GDM diagnosis proposed by the IADPSG were chosen by a cut-off where the OR for adverse outcomes (macrosomia, cesarean section, or a raised cord blood (-peptide) was $\geq 1.75$ and 1 abnormal glucose level was used for diagnosis [4]. The new proposal raised the frequency of GDM up to 3-fold in the HAPO cohort. We also found the rate of GDM increased 3-fold when we applied 1 abnormality with IADPSG cut-off values. However, the frequency of GDM diagnosed by IADPSG criteria was 7.5\%, much lower than in other reports (18.9-35.5\%), because we used the 2-step and not the 1-step approach [17-19]. In our study, the frequency of GDM by C-C criteria with a 2-step, $75 \mathrm{~g}$ 2-hour OGTT was 2.6\%. When a 2-step, $100 \mathrm{~g}$, 3-hour OGTT was applied, the frequency of GDM reported by Kore- 


\section{Obstetrics \& Gynecology Science}

Kyoung-Hee Lee, et al. Treatment of GDM by the IADPSG criteria

an studies was $1.9-4.0 \%$ by the NDDG criteria and 3.6-5.7\% by the C-C criteria, respectively $[21,22]$. The racial difference and lower BMI of Korean women may result in a lower incidence of GDM than that reported in other countries.

This study has several limitations with respect to the generalization of the results and the adoption of the new IADPSG criteria. We did not evaluate the cost-effectiveness of the new IADPSG criteria. However, in this study, it was remarkable that most women diagnosed with GDM (92.1\%) by 1 or more abnormal values of the IADPSG cut-off values succeeded in controlling glucose through nutritional education and exercise only. In contrast, one third of the women diagnosed with GDM by 2 abnormal values of the C-C cut-off values needed insulin therapy for glucose control. Although we used a 5-year study period, this study was conducted in a single institution, so the number of pregnant women with gestational diabetes was relatively small. The small sample size may affect the lack of difference in shoulder dystocia and birth tract injury associated with fetal overgrowth. Despite these limitations, this is the first study in Korea to prospectively assess the impact of the new IADPSG criteria on perinatal outcomes between treated and not-treated women.

In conclusion, women with GDM diagnosed solely by the IADPSG criteria, and not C-C criteria, also had an increased risk of LGA and macrosomia compared with the control group. However, the risk of excessive fetal growth was reduced if they were treated. This study suggests that the new IADPSG criteria identifies high risk groups for fetal overgrowth, and treatment based on the new criteria may be effective in reducing it.

\section{Acknowledgements}

This work received research funding from the Korea Centers for Disease Control and Prevention (2013-E63009-00, 2015ER-6302-00, 2016-ER6306-00, and 2016-ER6306-01).

\section{Conflict of interest}

No potential conflict of interest relevant to this article was reported.

\section{Ethical approval}

The Institutional Review Board of Cheil General Hospital (CGH-IRB-2013-10) approved the contents and research protocol.

\section{Patient consent}

This study was performed with informed patient consent.

\section{References}

1. O'Sullivan JB, Mahan CM. Criteria for the oral glucose tolerance test in pregnancy. Diabetes 1964;13:278-85.

2. Agarwal MM. Gestational diabetes mellitus: an update on the current international diagnostic criteria. World J Diabetes 2015;6:782-91.

3. HAPO Study Cooperative Research Group, Metzger BE, Lowe LP, Dyer AR, Trimble ER, Chaovarindr U, et al.; Hyperglycemia and adverse pregnancy outcomes. N Engl J Med 2008;358:1991-2002.

4. International Association of Diabetes and Pregnancy Study Groups Consensus Panel, Metzger BE, Gabbe SG, Persson B, Buchanan TA, Catalano PA, et al. International association of diabetes and pregnancy study groups recommendations on the diagnosis and classification of hyperglycemia in pregnancy. Diabetes Care 2010;33:676-82.

5. Diagnostic criteria and classification of hyperglycaemia first detected in pregnancy: a World Health Organization Guideline. Diabetes Res Clin Pract 2014;103:341-63.

6. Basevi V, Di Mario S, Morciano C, Nonino F, Magrini N. Comment on: American Diabetes Association. Standards of medical care in diabetes--2011. Diabetes Care 2011;34(Suppl. 1):S11-S61. Diabetes Care 2011;34:e53.

7. Committee on Practice Bulletins--Obstetrics. Practice Bulletin No. 137: Gestational diabetes mellitus. Obstet Gynecol 2013;122:406-16.

8. Kgosidialwa O, Egan AM, Carmody L, Kirwan B, Gunning $P$, Dunne FP. Treatment with diet and exercise for women with gestational diabetes mellitus diagnosed using IADPSG criteria. J Clin Endocrinol Metab 2015;100:4629-36. 


\section{Obstetrics \& Gynecology Science}

Vol. 63, No. 1, 2020

9. Bogdanet D, Egan AM, Reddin C, Kgosidialwa O, Kirwan B, Carmody L, et al. ATLANTIC DIP: insulin therapy for women with IADPSG-diagnosed gestational diabetes mellitus. Does it work? J Clin Endocrinol Metab 2017.102:849-57.

10. Wu ET, Nien FJ, Kuo CH, Chen SC, Chen KY, Chuang LM, et al. Diagnosis of more gestational diabetes lead to better pregnancy outcomes: comparing the International Association of the Diabetes and Pregnancy Study Group criteria, and the Carpenter and Coustan criteria. J Diabetes Investig 2016;7:121-6.

11. Maryns AS, Dehaene I, Page G. Maternal and neonatal outcomes in a treated versus non-treated cohort of women with gestational diabetes mellitus according to the HAPO 5 and 4 criteria. Facts Views Vis ObGyn 2017;9:133-40.

12. Carpenter MW, Coustan DR. Criteria for screening tests for gestational diabetes. Am J Obstet Gynecol 1982;144:768-73.

13. Lee JJ. Birth weight for gestational age patterns by sex, plurality, and parity in Korean population. Korean J Pediatr 2007;50:732-9.

14. Crowther CA, Hiller JE, Moss JR, McPhee AJ, Jeffries WS, Robinson JS, et al. Effect of treatment of gestational diabetes mellitus on pregnancy outcomes. N Engl J Med 2005;352:2477-86.

15. Landon MB, Spong CY, Thom E, Carpenter MW, Ramin SM, Casey B, et al. A multicenter, randomized trial of treatment for mild gestational diabetes. N Engl J Med 2009;361:1339-48.

16. Ethridge JK Jr, Catalano PM, Waters TP. Perinatal outcomes associated with the diagnosis of gestational diabetes made by the international association of the diabetes and pregnancy study groups criteria. Obstet Gynecol 2014;124:571-8.

17. Duran A, Sáenz S, Torrejón MJ, Bordiú E, Del Valle L, Galindo $M$, et al. Introduction of IADPSG criteria for the screening and diagnosis of gestational diabetes mellitus results in improved pregnancy outcomes at a lower cost in a large cohort of pregnant women: the St. Carlos Gestational Diabetes Study. Diabetes Care 2014;37:2442-50.

18. Wei Y, Yang H, Zhu W, Yang H, Li H, Yan J, et al. International Association of Diabetes and Pregnancy Study Group criteria is suitable for gestational diabetes mellitus diagnosis: further evidence from China. Chin Med J (Engl) 2014;127:3553-6.

19. Feldman RK, Tieu RS, Yasumura L. Gestational diabetes screening: the International Association of the Diabetes and Pregnancy Study Groups compared with carpentercoustan screening. Obstet Gynecol 2016;127:10-7.

20. Werner EF, Pettker CM, Zuckerwise L, Reel M, Funai EF, Henderson J, et al. Screening for gestational diabetes mellitus: are the criteria proposed by the international association of the Diabetes and Pregnancy Study Groups cost-effective? Diabetes Care 2012;35:529-35.

21. Lee JH, Lee HJ, Lee JG, Hwang JH, Kim SR, Kim KT, et al. A comparison of criteria of gestational diabetes using $100 \mathrm{gm}$ oral glucose tolerance test in Korean women. Korean J Obstet Gynecol 2005;48:2570-7.

22. Yang SC, Kim HS, Yang JI, Lee HJ, Ahn ST, Seo SS, et al. Study of the diagnostic criteria for gestational diabetes mellitus. Korean J Obstet Gynecol 2002;45:1932-9. 